\begin{tabular}{c}
\hline TÜRK \\
TARIM ve DOĞA BİLIMLERI \\
DERGISI \\
\hline \hline
\end{tabular}

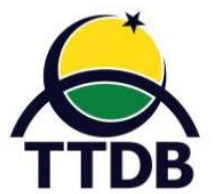

www.dergipark.gov.tr/turkjans Araştırma Makalesi
TURKISH

JOURNAL Of AGRICULTURAL and NATURAL SCIENCES

\title{
Rize İlinde Yetişen Cennet Hurması Örneklerinde Doğal ve Yapay Radyonüklitlerin Aktivite Konsantrasyonlarının Belirlenmesi ve Yıllık Etkin Doz Değerleri
}

\author{
Nilay AKÇAY \\ Recep Tayyip Erdoğan Üniversitesi Fen Edebiyat Fakültesi Fizik Bölümü, Rize, Türkiye \\ Sorumlu yazar: nilay.akcay@erdogan.edu.tr
}

Geliş Tarihi: 27.09.2019 Düzeltme Geliş Tarihi: 25.05.2020 Kabul Tarihi: 28.05.2020

$\overline{\mathrm{Ozz}}$

Dünyanın pek çok bölgesinde, meyve örneklerindeki radyonüklitlerin radyasyon aktivitelerinin belirlenmesi ve bu aktivitelerden maruz kalınan yıllık etkin doz değerlerinin hesaplanması ile ilgili araştırmalar yapılmaktadır. Ancak, Cennet Hurması (Diospyros kaki L.) meyvesindeki radyonüklitlerin radyasyon aktivite düzeyleri hakkında yeterli miktarda veriye rastlanmamaktadır. Bu çalışmada Rize ilinde yetişen Cennet hurması örneklerinde doğal $\left({ }^{238} \mathrm{U},{ }^{232} \mathrm{Th},{ }^{40} \mathrm{~K}\right)$ ve yapay $\left({ }^{137} \mathrm{Cs}\right)$ radyonüklitlerin aktivite konsantrasyonlarının belirlenmesi ve bu meyvenin tüketiminden yöre halkının maruz kalabilecekleri yılık etkin doz değerlerinin hesaplanması amaçlanmıştır. Örneklerin analizi için yüksek saflıkta germanyum dedektörü (HPGe) ve gama spektrometre sistemi kullanılmış olup, örneklerdeki ${ }^{238} \mathrm{U}$, ${ }^{232} \mathrm{Th},{ }^{137} \mathrm{Cs}$ ve ${ }^{40} \mathrm{~K}$ radyonüklitleri için ortalama aktivite konsantrasyonları sırasıyla $5.01 \pm 0.48 \mathrm{~Bq} \mathrm{~kg}$, $5.87 \pm 0.93 \mathrm{~Bq} \mathrm{~kg}^{-1}, 21.25 \pm 0.74 \mathrm{~Bq} \mathrm{~kg}^{-1}$ ve $1438.69 \pm 22.14 \mathrm{~Bq} \mathrm{~kg}^{-1}$ olarak bulunmuştur. Ayn radyonüklitler için ortalama yıllık etkin doz değerleri sırasıyla $0.632 \mu \mathrm{Sv}^{-1}, 3.787 \mu \mathrm{Sv} \mathrm{y}^{-1}, 0.774 \mu \mathrm{Sv} \mathrm{y}^{-1}$ ve $24.976 \mu \mathrm{Sv}$ $\mathrm{y}^{-1}$ olarak elde edilmiştir. Toplam yıllık etkin doz değerleri $18.215 \mu \mathrm{Sv} \mathrm{y}^{-1}$ ile $45.990 \mu \mathrm{Sv} \mathrm{y}^{-1}$ aralığında hesaplanmıştır. Bu değerler, Birleşmiş Milletler Atomik Radyasyonun Etkileri Bilimsel Komitesi (UNSCEAR) tarafından belirtilen, insanların doğal radyoaktif kaynaklardan gıda yoluyla maruz kaldıkları yıllık ortalama radyasyon dozu olan 0.29 mSv değerinden oldukça düşük olup halk sağlığı açısından herhangi bir risk teşkil etmemektedir.

Anahtar Kelimeler: Cennet hurması, Radyonüklit, Aktivite, Yıllık Etkin Doz, Rize

Determination of Activity Concentrations of Natural and Artificial Radionuclides in Diospyros kaki L. Samples Grown in Rize Province and Annual Effective Dose Values

\begin{abstract}
In many regions of the world, researches are carried out to determine the radiation activities of radionuclides in fruit samples and to calculate the annual effective dose values exposed from these activities. However, there is not enough data about the radiation activity levels of radionuclides in the Diospyros kaki L. fruit. In this study it was aimed to determine the activity concentrations of natural $\left({ }^{238} \mathrm{U},{ }^{232} \mathrm{Th},{ }^{40} \mathrm{~K}\right)$ and artificial $\left({ }^{137} \mathrm{Cs}\right)$ radionuclides in the Diospyros kaki L. samples grown in Rize province and to calculate the annual effective dose values that the local people are exposed from the consumption of this fruit. The high purity germanium detector (HPGe) and gamma spectrometry system were used for the analysis of the samples, and the average activity concentrations for the ${ }^{238} \mathrm{U},{ }^{232} \mathrm{Th}$, ${ }^{137} \mathrm{Cs}$ and ${ }^{40} \mathrm{~K}$ radionuclides in the samples were found as $5.01 \pm 0.48 \mathrm{~Bq} \mathrm{~kg}$, $5.87 \pm 0.93 \mathrm{~Bq} \mathrm{~kg}$, $21.25 \pm 0.74 \mathrm{~Bq} \mathrm{~kg}^{-1}$ and $1438.69 \pm 22.14 \mathrm{~Bq} \mathrm{~kg}^{-1}$, respectively. The mean annual effective dose values for the same radionuclides were obtained as $0.632 \mu \mathrm{Sv}^{-1}, 3.787 \mu \mathrm{Sv} \mathrm{y}^{-1}, 0.774 \mu \mathrm{Sv} \mathrm{y}^{-1}$ and $24.976 \mu \mathrm{Sv} \mathrm{y}^{-1}$, respectively. The total annual effective dose values were calculated between $18.215 \mu \mathrm{Sv} \mathrm{y}^{-1}$ and 45.990 $\mu \mathrm{Sv} \mathrm{y}^{-1}$. These values are considerably lower than the annual average radiation dose of $0.29 \mathrm{mSv}$, which is specified by the United Nation Scientific Committe on the Effects of Atomic Radiation (UNSCEAR), to which people are exposed from natural radioactive sources in foodstuff, and poses no risk to public health.
\end{abstract}

Key Words: Diospyros kaki L., Radionuclide, Activity, Annual Effective Dose, Rize 


\section{Giriş}

Cennet hurması (Diospyros kaki L.), abanozgiller (Ebenaceae) familyasına ait, pürüzsüz ve parlak kabuklu, turuncu renkli bir meyvedir (Sargın ve ark., 2013; Vardal, 2009). Yapısında bulunan tanen, meyveye buruk bir tat vermektedir (Jackson, 1986; Öz ve Özelkök, 2003). Yeterince olgunlaşmış ve burukluğu giderilmiş meyveler taze veya kurutularak tüketilebildiği gibi, taze tüketime uygun olmayanlar yeterli dondurucu ve muhafaza şartları altında depolanarak gıda sanayisinde jöle, sos, nektar, dondurma, krema, marmelat, sakız ve püre yapımında kullanılmaktadır (Karaaslan, 2014; Onur ve Onur, 1997; Özdemir ve ark., 2014). Cennet hurması, antioksidan özelliklere sahip olması, düşük kalori içermesi ve kolesterolü arttırmayan etki göstermesinden dolayı doğal beslenmeye önem verilen ekonomik düzeyleri yüksek ülkelerde geleceğin meyvesi olarak tanımlanmaktadır (Çalışkan ve Dirim, 2015; Kaplankıran, 2011; Yıldız ve ark., 2012). Ayrıca bağışıklık sistemini güçlendirdiği, kansızlığa ve sindirim sistemi rahatsızlıklarına iyi geldiği ve bazı kanser ve sinir sistemi hastalıklarından korunmada etkili olduğu için kişisel sağlıklarına özen gösteren tüketiciler tarafından her geçen gün artan bir talep oluşturmaktadır (Butt ve ark., 2015; Kuzucu, 2003; Parseker ve ark., 2008). Cennet hurmasının dünyadaki yıllık üretimi 5190624 tondur (Anonymous, 2017; Özcan, 2018 ). Başlıca üretici ülkeler; Çin (3 730800 ton), Kore Cumhuriyeti (428 363 ton), İspanya (245 000 ton), Japonya (240 600 ton), Brezilya (182 290 ton), Azerbaycan (140 405 ton), Özbekistan (66 000 ton) ve İtalya (39 149 ton)'dır (Anonymous, 2017; Özcan, 2018 ). Türkiye'deki yıllık üretim ise 1990 yılı verilerine göre 10000 ton iken, 2016 yılı verilerine göre, \%247 düzeyinde artış göstererek 34650 tona ulaşmıştır (Anonim, 2017; Özcan, 2018).

Çizelge 1'de Dünyadaki Cennet hurması üretiminde başlıca üretici ülkelerin yıllara göre üretim miktarları ve Çizelge 2'de Türkiye'deki Cennet hurması üretiminde yıllara göre gelişme verileri gösterilmiştir.

Çizelge 1. Dünyadaki Cennet hurması üretiminde başlıca üretici ülkelerin yıllara göre üretim miktarları (Anonymous, 2017; Özcan, 2018)

\begin{tabular}{|c|c|c|c|c|c|}
\hline \multirow[b]{2}{*}{ Üllkeler } & \multicolumn{4}{|c|}{ Üretim miktarı (ton) } & \multirow[b]{2}{*}{2014} \\
\hline & 1995 & 2000 & 2005 & 2010 & \\
\hline Çin & 969363 & 1591906 & 2185041 & 2875600 & 3730800 \\
\hline Kore Cum. & 194585 & 287847 & 363822 & 390630 & 428363 \\
\hline İspanya & 10826 & 33000 & 51950 & 125280 & 245000 \\
\hline Japonya & 254100 & 278800 & 285900 & 189400 & 240600 \\
\hline Brezilya & 51685 & 63300 & 164849 & 167215 & 182290 \\
\hline Azerbaycan & - & 70300 & 108965 & 142188 & 140405 \\
\hline Özbekistan & - & 16000 & 21000 & 38000 & 66000 \\
\hline İtalya & 61300 & 42450 & 51332 & 48165 & 39149 \\
\hline Türkiye & 9200 & 12000 & 18000 & 26277 & 33470 \\
\hline Diğer ülkeler & 22362 & 32043 & 63872 & 67620 & 84547 \\
\hline Toplam & 1573421 & 2427646 & 3314731 & 4070375 & 5190624 \\
\hline
\end{tabular}

Çizelge 2. Türkiye'deki Cennet hurması üretiminde yıllara göre gelişme verileri (Anonim, 2017; Özcan, 2018)

\begin{tabular}{cccccc}
\hline & \multicolumn{3}{c}{ Ağaç sayısı (1000 adet) } & & \\
\cline { 2 - 4 } Yıllar & Meyve veren yaşta & Meyve vermeyen yaşta & Toplam & Üretim (ton) & $\begin{array}{c}\text { Verim } \\
\text { (kg/ağaç) }\end{array}$ \\
\hline 1990 & 284 & 86 & 370 & 10000 & 35 \\
1995 & 344 & 114 & 458 & 9200 & 27 \\
2000 & 500 & 165 & 665 & 12000 & 24 \\
2005 & 590 & 195 & 785 & 18000 & 31 \\
2010 & 734 & 194 & 928 & 26277 & 36 \\
2015 & 860 & 197 & 1057 & 33725 & 39 \\
2016 & 865 & 276 & 1141 & 34650 & 40 \\
\hline
\end{tabular}


Cennet hurması Türkiye'de çok eski yıllardan beri yetiştirilmekte olup yöreler arasında isim farklılıkları göstererek Amme, Frenk elması, Japon elması, Trabzon hurması ve Rize hurması olarak adlandırılmaktadır (Onur, 1985; Yıldız ve ark., 2012). Genellikle Akdeniz, Karadeniz, Marmara ve Ege Bölgelerindeki illerde tek ağaç ya da küçük parseller içinde yetiştirilen Cennet hurması için son yıllarda artan talepler doğrultusunda yeni bahçeler oluşturulmakta ve alternatif meyve olarak tarım sahalarında yaygınlaştırma çalışmaları devam etmektedir (Onur, 1990; Toplu ve ark., 2016; Tuzcu ve Yıldırım, 2000).

Çizelge 3'te Türkiye'deki Cennet hurması üretiminin bölgelere göre dağılımı ile ilgili veriler gösterilmiştir. Çizelge 4 ve Çizelge 5 'de sırası ile, Türkiye'deki Cennet hurması üretiminde önemli bazı illerin yıllara göre üretim alanları ve üretim miktarları verilmiştir.

Çizelge 3. Türkiye'deki Cennet hurması üretiminin bölgelere göre dağılımı (Anonim, 2017; Özcan, 2018)

\begin{tabular}{lccc}
\hline Bölge & $\begin{array}{c}\text { Üretim } \\
\text { (ton) }\end{array}$ & Üretimdeki payı (\%) & Ağaç verimi (kg/ağaç) \\
\hline Akdeniz & 17040 & 49.18 & 46 \\
Ege & 5815 & 16.78 & 35 \\
Doğu Marmara & 4146 & 11.97 & 46 \\
Güneydoğu Anadolu & 2558 & 7.38 & 26 \\
Doğu Karadeniz & 2131 & 6.15 & 33 \\
Batı Karadeniz & 1290 & 3.72 & 50 \\
Batı Marmara & 1157 & 3.34 & 51 \\
Ortadoğu Anadolu & 310 & 0.90 & 20 \\
Kuzeydoğu Anadolu & 77 & 0.22 & 23 \\
Batı Anadolu & 73 & 0.21 & 72 \\
İstanbul & 53 & 0.15 & 19 \\
Toplam & 34650 & 100 & $\sim 40$ \\
\hline
\end{tabular}

Çizelge 4. Türkiye'deki Cennet hurması üretiminde önemli bazı illerin yıllara göre üretim alanları (Anonim, 2016a)

\begin{tabular}{lccccccc} 
& \multicolumn{7}{c}{ Üretim alanı (dekar) } \\
\cline { 2 - 8 } Iller & 2010 & 2011 & 2012 & 2013 & 2014 & 2015 & 2016 \\
\hline Adana & 3713 & 4034 & 4092 & 4066 & 4035 & 3235 & 4107 \\
İzmir & 75 & 100 & 102 & 100 & 250 & 250 & 315 \\
Mersin & 3210 & 3176 & 3266 & 3285 & 3415 & 3525 & 3505 \\
Hatay & 4466 & 4496 & 4562 & 4554 & 1674 & 1675 & 2074 \\
Yalova & 265 & 310 & 389 & 717 & 912 & 912 & 926 \\
Denizli & 2374 & 2664 & 2733 & 2812 & 3439 & 3914 & 3814 \\
Adıyaman & 1131 & 1157 & 1108 & 1634 & 1630 & 1633 & 1695 \\
Kahramanmaraş & 1150 & 1076 & 1144 & 1144 & 940 & 945 & 1211 \\
Sakarya & 312 & 493 & 494 & 495 & 471 & 569 & 631 \\
Gaziantep & 1245 & 1255 & 868 & 802 & 751 & 751 & 751 \\
Artvin & 3 & 43 & 44 & 43 & 43 & 43 & 45 \\
Rize & 140 & 140 & 144 & 144 & 147 & 147 & 147 \\
Trabzon & 289 & 291 & 292 & 292 & 299 & 228 & 218 \\
Türkiye & 19741 & 20900 & 21317 & 22642 & 20619 & 20789 & 23024 \\
\hline
\end{tabular}


Çizelge 5. Türkiye'deki Cennet hurması üretiminde önemli bazı illerin yıllara göre üretim miktarları (Anonim, 2016a)

\begin{tabular}{lccccccc} 
& \multicolumn{7}{c}{ Üretim miktarı (ton) } \\
\hline iller & 2010 & 2011 & 2012 & 2013 & 2014 & 2015 & 2016 \\
\hline Adana & 4784 & 7177 & 7760 & 8694 & 8586 & 9215 & 8374 \\
İzmir & 336 & 318 & 340 & 328 & 3989 & 4043 & 4123 \\
Mersin & 4219 & 3915 & 4256 & 3731 & 3532 & 3642 & 3507 \\
Hatay & 5881 & 6292 & 6281 & 5585 & 3306 & 3245 & 3249 \\
Yalova & 281 & 293 & 654 & 1081 & 1434 & 1379 & 1742 \\
Denizli & 2460 & 1524 & 2310 & 2436 & 2278 & 693 & 1457 \\
Adıyaman & 1011 & 1099 & 1272 & 1302 & 1348 & 1438 & 1435 \\
Kahramanmaraş & 1633 & 1642 & 1843 & 1873 & 1514 & 1363 & 1262 \\
Sakarya & 680 & 675 & 697 & 716 & 994 & 1046 & 1134 \\
Gaziantep & 619 & 641 & 1254 & 1267 & 866 & 1118 & 1091 \\
Artvin & 944 & 1015 & 1026 & 1002 & 921 & 866 & 863 \\
Rize & 148 & 174 & 193 & 245 & 233 & 231 & 211 \\
Trabzon & 96 & 108 & 151 & 162 & 91 & 131 & 144 \\
Türkiye & 26277 & 28295 & 32392 & 33232 & 33470 & 33725 & 34650 \\
\hline
\end{tabular}

Rize ili Doğu Karadeniz Bölgesinde bulunan ve Cennet hurmasının yetiştirildiği bir ildir. İlin özellikle denize kıyı ilçelerindeki bahçelerde doğal olarak yetişen Cennet hurması ağaçları bol ve kaliteli ürünler vermektedir. Yöre halkı tarafından toplanan meyveler, pazara sunularak, kurutularak, taze (yaş) olarak ya da pekmez veya marmelatları yapılarak tüketilmektedir. Çizelge 4 ve Çizelge 5 'deki Türkiye İstatistik Kurumu (TUIK) verilerine göre, 2016 yılında Rize ilinde 147 dekar alanda 211 ton Cennet hurması üretimi gerçekleştirilmiştir (Anonim, 2016a).

Rize ili Çernobil Nükleer Santral Kazası'ndan etkilenmiş bir ildir. 26 Nisan 1986 tarihinde meydana gelen Çernobil Nükleer Santral Kazası'ndan sonra oluşan radyoaktif bulutların bir kısmı Avrupa'nın kuzey, doğu ve batısına doğru ilerlerken bir kısmı da güneye doğru inerek Türkiye'nin Batı Trakya Bölgesi ve Rize'nin de içinde bulunduğu Doğu Karadeniz Bölgesi'nde etkili olmuştur.

Çernobil Nükleer Santral Kazası'ndan sonra çevreye yarı ömürleri gün ve haftalarla ifade edilebilecek İyot-131 ( ${ }^{131}$ I) ve Tellüryum$132\left({ }^{132} \mathrm{Te}\right)$ gibi nispeten kısa yarı ömürlü radyonüklitlerle beraber Sezyum-137 $\left({ }^{137} \mathrm{Cs}\right)$ gibi yarı ömrü 30 yıl mertebesinde olan uzun yarı ömürlü radyonüklitler de yayınlanmıştır (Anonymous, 2003). Kısa yarı ömürlü radyonüklitler kazayı izleyen ilk birkaç ay içerisinde çevreden kaybolmasına rağmen ${ }^{137} \mathrm{Cs}$, 30 yıl yarı ömre sahip olmasından dolayı halen bazı bitkilerde tespit edilmeye devam etmektedir.

${ }^{137} \mathrm{Cs}$, nükleer santrallerin normal işletimleri sırasında, yakıt çubuklarındaki Uranyum atomlarının fisyonuyla üretilmektedir (Anonymous, 2004a). Nükleer kaza ve patlamalar sonucu atmosfere yayılabilen ${ }^{137} \mathrm{Cs}$, yağmur sularıyla toprağa süzülebilmekte, bitkilerin bünyelerine alınabilmekte, bu bitkileri tüketen insanların vücuduna taşınabilmekte ve bazı doku ve organlarda haftalarca veya aylarca kalabilmektedir.

${ }^{137} \mathrm{Cs}$ yapay radyoaktif bir element olup kararlı hale gelebilmek için 661 keV enerjisinde gama radyasyonu yayınlamaktadır. ${ }^{137} \mathrm{Cs}$ tarafından yayılan gama radyasyonu, insanların yapay radyasyon kaynaklarından dahili olarak aldıkları radyasyon doz değerine katkıda bulunmaktadır.

Dünya genelinde insanların doğal ve yapay radyasyon kaynaklarından maruz kaldıkları ortalama radyasyon dozu $2.8 \mathrm{mSv}$ y${ }^{1}$ dır. Bunun \%14'ü $\left(0.4 \mathrm{mSv} \quad \mathrm{y}^{-1}\right)$ yapay radyasyon kaynaklarına ve \%86'sı (2.4 mSv $\mathrm{y}^{-1}$ ) doğal radyasyon kaynaklarına aittir (Anonymous, 2004b).

Uranyum-238 $\left({ }^{238} \mathrm{U}\right)$, Toryum-232 (232 $\left.\mathrm{Th}\right)$ ve Potasyum-40 $\left({ }^{40} \mathrm{~K}\right)$ başlıca doğal radyasyon kaynakları olup dünyanın var oluşundan bu yana bitkilerin yapılarında doğal olarak yerlerini almışlardır. Sindirim yolu ile ${ }^{238} \mathrm{U},{ }^{232} \mathrm{Th}$ ve ${ }^{40} \mathrm{~K}$ radyonüklitleri tarafından maruz kalınan radyasyon dozu, bölgeden bölgeye, beslenme alışkanlıklarına, tüketim miktarına ve 
radyonüklitlerin konsantrasyonuna göre değişiklik göstermektedir. Yapılarında ${ }^{238} \mathrm{U}$, ${ }^{232} \mathrm{Th}$ ve ${ }^{40} \mathrm{~K}$ bulunduran gıdaların tüketilmesiyle insanların dahili olarak maruz kaldıkları yılık ortalama doğal radyasyon dozu $0.29 \mathrm{mSv}(290$ $\mu \mathrm{Sv})^{\prime}$ dir. Bunun $\% 58.6^{\prime} \mathrm{sI} \quad(0.17 \mathrm{mSv}){ }^{40} \mathrm{~K}$ radyonüklitine ve $\% 41.3^{\prime}$ ü $(0.12 \mathrm{mSv}){ }^{238} \mathrm{U}$ ve ${ }^{232} \mathrm{Th}$ serisi radyonüklitlere aittir (Anonymous, $2000)^{238} \mathrm{U},{ }^{232} \mathrm{Th},{ }^{137} \mathrm{Cs}$ ve ${ }^{40} \mathrm{~K}$ radyonüklitleri tarafından yayınlanan gama radyasyonları uzun vadede insan sağlığı açısından olumsuz etkiler oluşturabileceği için, gıda örneklerindeki doğal $\left({ }^{238} \mathrm{U}, \quad{ }^{232} \mathrm{Th},{ }^{40} \mathrm{~K}\right)$ ve yapay $\left({ }^{137} \mathrm{Cs}\right)$ radyonüklitlerin aktivite konsantrasyonlarının belirlenmesi, bu gıda maddelerini tüketen kişilerin maruz kaldıkları radyasyon dozunun değerlendirilmesi açısından önemlidir. Pek çok çalışmada Cennet hurmasının $A, C$ ve $E$ vitaminleri bakımından zengin olduğu, bol miktarda karbonhidrat, beta karoten, suda eriyebilen lifler ve antioksidan maddeler içerdiği belirtilmesine rağmen (Kuzucu, 2003; Aktepe ve ark., 2010; Tuzcu ve Yıldırım, 2000), Cennet hurmasının gerek Türkiye'de gerekse diğer ülkelerde radyonüklit içerikleri ve radyasyon aktivite düzeyleri hakkında fazla sayıda veriye rastlanmamaktadır.

Bu çalışmada Rize ilinde yetişen Cennet hurması örneklerinde doğal $\left({ }^{238} \mathrm{U},{ }^{232} \mathrm{Th},{ }^{40} \mathrm{~K}\right)$ ve yapay $\left({ }^{137} \mathrm{Cs}\right)$ radyonüklitlerin aktivite konsantrasyonlarının belirlenmesi ve bu meyvenin tüketiminden yöre halkının maruz kalabilecekleri yıllık etkin doz değerlerinin hesaplanması amaçlanmıştır. Elde edilen sonuçlar uluslararası kuruluşlar tarafından ifade edilen ortalama ve limit değerlerle karşılaştırılmıştır. Şu ana kadar Rize ilindeki Cennet hurması örnekleri kullanılarak yapılmış bu tarz bir çalışmaya rastlanmamaktadır. Bu anlamda bu çalışma ulusal ve uluslararası literatür için temel bir veri olmada katkı sağlayacak ve ileriki yıllarda çeşitli bölgelerde yapılan çalışmalardan elde edilen sonuçlar ile karşılaştırma fırsatı oluşturacaktır.

\section{Materyal ve Yöntem}

Rize ili, Doğu Karadeniz Bölgesinin doğusunda, $40^{\circ} 22^{\prime}$ ve $41^{\circ} 28^{\prime}$ doğu meridyenleri ile $40^{\circ} 20^{\prime}$ ve $41^{\circ} 20^{\prime}$ kuzey paralelleri arasında yer alan 331048 nüfuslu bir ildir. Batıdan Trabzon'un Of ilçesi ile, güneyden Erzurum'un İspir ilçesi ile, doğudan Artvin'in Yusufeli ve Arhavi ilçeleri ile ve kuzeyden Karadeniz ile çevrilidir. Rize ilinin göller hariç yüzölçümü $3920 \mathrm{~km}^{2}$ dir ve denize kıyı şeridinin uzunluğu 80 km'dir. Çok dar olan bu kıyı şeridinin genişliği akarsu vadileri dışında ortalama 20$150 \mathrm{~m}$ arasında değişiklik göstermektedir. Genellikle dağlık ve engebeli olan Rize ili arazisi, kıyı düzlüğünün hemen gerisinde yükselmekte ve yükseltisi birdenbire 150-200 m’yi bulmaktadır. Kıyıdan yaklaşık 750 m yüksekliğe kadar olan geniş saha kıyı ormanları ile kaplıdır. $\mathrm{Bu}$ sahada yerleşim yerlerinin yanı sıra yer yer kayın, kestane, ıhlamur, gürgen, defne, çınar, meşe ve şimşir ağaçları yetişmektedir. Cennet hurması ise bu alanlarda yetişen ağaç türlerden bir diğeridir (Anonim, 2019).

Rize ili, Türkiye'deki Cennet hurması üretiminde, önemli kapasiteye sahip illerden biridir. Bu çalışmada Rize ilinde yetişen Cennet hurması örneklerindeki doğal $\left({ }^{238} \mathrm{U},{ }^{232} \mathrm{Th},{ }^{40} \mathrm{~K}\right)$ ve yapay $\left({ }^{137} \mathrm{Cs}\right)$ radyonüklitlerin aktivite konsantrasyonlarının belirlenmesi ve bu meyvenin tüketiminden yöre halkının maruz kalabilecekleri yıllık etkin doz değerlerinin hesaplanması amaçlanmıştır. $\mathrm{Bu}$ amaçla 80 km'lik Rize ili kıyı şeridi boyunca İyidere, Derepazarı, Rize Merkez ilçe, Çayeli, Pazar, Ardeşen ve Fındıklı ilçelerinden 3 'er istasyondan Cennet hurması örnekleri toplanmıştır. Toplanan örneklere ait istasyonlar Şekil 1'de gösterilmiştir ve istasyonların koordinat bilgileri Çizelge 6'da belirtilmiştir.

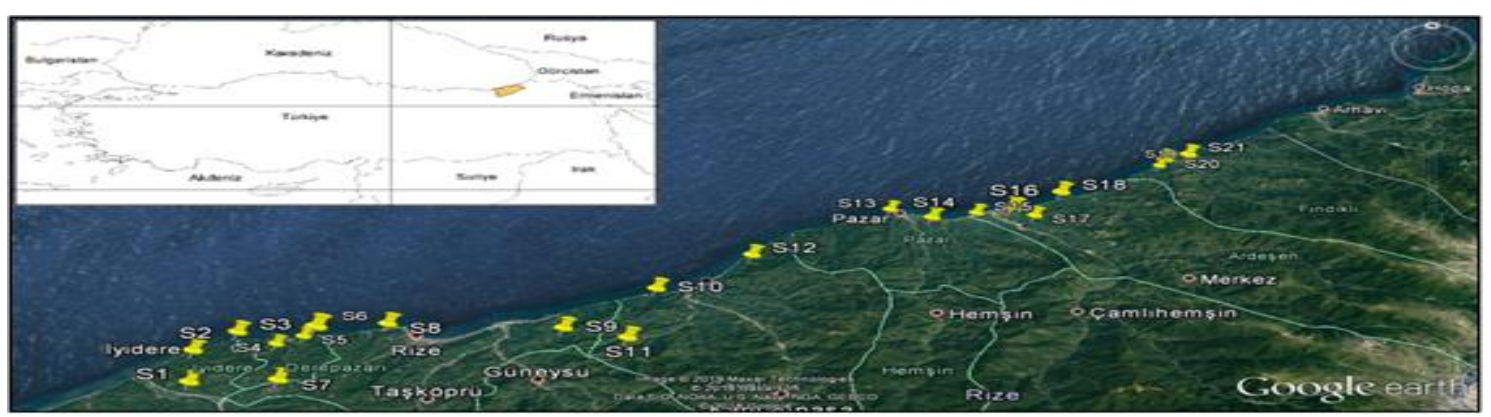

Şekil 1. Cennet hurması örneklerinin toplandığı istasyonlar 
Çizelge 6. Cennet hurması örneklerinin toplandığı istasyonların koordinat bilgileri

\begin{tabular}{|c|c|c|c|}
\hline No & ìlçe & İstasyon & Koordinatlar \\
\hline $\mathrm{S} 1$ & & Denizgören & $40^{\circ} 58^{\prime} 15.4^{\prime \prime} \mathrm{K} ; 40^{\circ} 22^{\prime} 7.6^{\prime \prime} \mathrm{D}$ \\
\hline $\mathrm{S} 2$ & İyidere & Fıçıtaşı & $41^{\circ} 00^{\prime} 14.0^{\prime \prime} \mathrm{K} ; 40^{\circ} 21^{\prime} 35.0^{\prime \prime} \mathrm{D}$ \\
\hline S3 & & Sarayköy & $41^{\circ} 01^{\prime} 28.7^{\prime \prime} \mathrm{K} ; 40^{\circ} 23^{\prime} 03.4^{\prime \prime} \mathrm{D}$ \\
\hline S4 & & Fıçıcılar & $41^{\circ} 00^{\prime} 40.3^{\prime \prime} \mathrm{K} ; 40^{\circ} 25^{\prime} 01.5^{\prime \prime} \mathrm{D}$ \\
\hline S5 & Derepazarı & Sayıyer & $41^{\circ} 01^{\prime} 14.8^{\prime \prime} \mathrm{K} ; 40^{\circ} 26^{\prime} 02.4^{\prime \prime} \mathrm{D}$ \\
\hline S6 & & Bürücek & $41^{\circ} 01^{\prime} 42.8^{\prime \prime} \mathrm{K} ; 40^{\circ} 26^{\prime} 22.8^{\prime \prime} \mathrm{D}$ \\
\hline S7 & & Kendirli & $40^{\circ} 58^{\prime} 20.6^{\prime \prime} \mathrm{K} ; 40^{\circ} 25^{\prime} 49.8^{\prime \prime} \mathrm{D}$ \\
\hline S8 & $\begin{array}{l}\text { Merkez } \\
\text { Illçe }\end{array}$ & Fener & $41^{\circ} 01^{\prime} 58.9^{\prime \prime} \mathrm{K} ; 40^{\circ} 29^{\prime} 30.7^{\prime \prime} \mathrm{D}$ \\
\hline S9 & & Veliköy & $41^{\circ} 01^{\prime} 39.0^{\prime \prime} \mathrm{K} ; 40^{\circ} 37^{\prime} 16.6^{\prime \prime} \mathrm{D}$ \\
\hline S10 & & Limanköy & $41^{\circ} 04^{\prime} 29.5^{\prime \prime} \mathrm{K} ; 40^{\circ} 41^{\prime} 10.7^{\prime \prime} \mathrm{D}$ \\
\hline S11 & Çayeli & Büyükköy & $41^{\circ} 00^{\prime} 58.9^{\prime \prime} \mathrm{K} ; 40^{\circ} 40^{\prime} 07.7^{\prime \prime} \mathrm{D}$ \\
\hline S12 & & Kesmetaş & $41^{\circ} 06^{\prime} 58.7^{\prime \prime} \mathrm{K} ; 40^{\circ} 45^{\prime} 33.7^{\prime \prime} \mathrm{D}$ \\
\hline S13 & & Hisarlı & $41^{\circ} 10^{\prime} 52.5^{\prime \prime} \mathrm{K} ; 40^{\circ} 52^{\prime} 31.6^{\prime \prime} \mathrm{D}$ \\
\hline S14 & Pazar & Kirazlık & $41^{\circ} 10^{\prime} 04.0^{\prime \prime} \mathrm{K} ; 40^{\circ} 54^{\prime} 29.3^{\prime \prime} \mathrm{D}$ \\
\hline S15 & & Hamidiye & $41^{\circ} 10^{\prime} 33.4^{\prime \prime} \mathrm{K} ; 40^{\circ} 56^{\prime} 47.3^{\prime \prime} \mathrm{D}$ \\
\hline S16 & & Gazi Caddesi & $41^{\circ} 10^{\prime} 46.4^{\prime \prime} \mathrm{K} ; 40^{\circ} 58^{\prime} 31.4^{\prime \prime} \mathrm{D}$ \\
\hline S17 & Ardeşen & Pirinçlik & $41^{\circ} 10^{\prime} 16.8^{\prime \prime} \mathrm{K} ; 40^{\circ} 59^{\prime} 37.4^{\prime \prime} \mathrm{D}$ \\
\hline S18 & & Işıklı & $41^{\circ} 12^{\prime} 16.1^{\prime \prime} \mathrm{K} ; 41^{\circ} 01^{\prime} 20.9^{\prime \prime} \mathrm{D}$ \\
\hline S19 & & Yeniköy & $41^{\circ} 01^{\prime} 14.8^{\prime \prime} \mathrm{K} ; 40^{\circ} 26^{\prime} 02.4^{\prime \prime} \mathrm{D}$ \\
\hline S20 & Fındıklı & Sahil & $41^{\circ} 15^{\prime} 21.7^{\prime \prime} \mathrm{K} ; 41^{\circ} 07^{\prime} 32.0^{\prime \prime} \mathrm{D}$ \\
\hline $\mathrm{S} 21$ & & Dereüstü & $41^{\circ} 15^{\prime} 50.3^{\prime \prime} \mathrm{K} ; 41^{\circ} 08^{\prime} 56.1^{\prime \prime} \mathrm{D}$ \\
\hline
\end{tabular}

İstasyonlardan toplanan Cennet hurması örnekleri 1 kg'lık plastik poşetlere konularak laboratuvara nakledilmiştir ve 12 saat boyunca $400{ }^{\circ} C^{\prime} y e$ ayarlanmış fırında kül haline getirilmiştir. Kül haline getirilmiş numuneler 1 $\mathrm{mm}$ 'lik elekten geçirilerek hassas terazi ile tartılmış ve vida kapaklı 100 ml'lik plastik şeffaf numune kutularına konularak muhafaza edilmişlerdir. Numune kutularının üzerlerine örneklerin istasyon numaraları, kütleleri ve yakılma tarihleri yazılmıştır. Her bir numune iyice kapatılarak, ${ }^{226} \mathrm{Ra}$ ve ${ }^{222} \mathrm{Rn}$ arasındaki radyoaktif dengenin oluşması için 1 ay boyunca bekletilmiştir.

Radyoaktivite analizlerinin yapılabilmesi için hazır hale getirilen örneklerin gama radyoaktivite analizleri Recep Tayyip Erdoğan Üniversitesi Fen Edebiyat Fakültesi Fizik Bölümü Nükleer Fizik Laboratuvarı'ndaki yüksek saflıkta
Germanyum (High Purity Germanium) detektör sistemi kullanılarak gerçekleştirilmiştir. Cennet hurması örneklerindeki ${ }^{238} \mathrm{U},{ }^{232} \mathrm{Th},{ }^{137} \mathrm{Cs}$ ve ${ }^{40} \mathrm{~K}$ radyonüklitlerinin aktivite konsantrasyonlarını belirlemek için Şekil 2'de gösterilen yüksek saflıkta germanyum (HPGe Ortec Gem55P4-95) dedektör sistemi, çok kanallı analizör ve Ortec Maestro 32 yazılımı kullanılmıştır. Ayrıca örneklerin analizi için Genie 2000 programından yararlanılmıştır.

HPGe dedektörünün tavsiye edilen çalışma voltajı $4800 \mathrm{~V}$ olup, yarıçapı $7.76 \mathrm{~cm}$, yüksekliği $3.97 \mathrm{~cm}$ ve bağıl verimi $\% 55^{\prime}$ dir (Anonymous, 2008). Dedektör sisteminin soğutulması için 30 It hacminde azot tankı kullanılmıştır ve ortamdaki fon (background) radyasyonunun en aza indirilmesi için dedektör, $10 \mathrm{~cm}$ kalınlığında kurşun zırh ile zırhlanmıştır. 

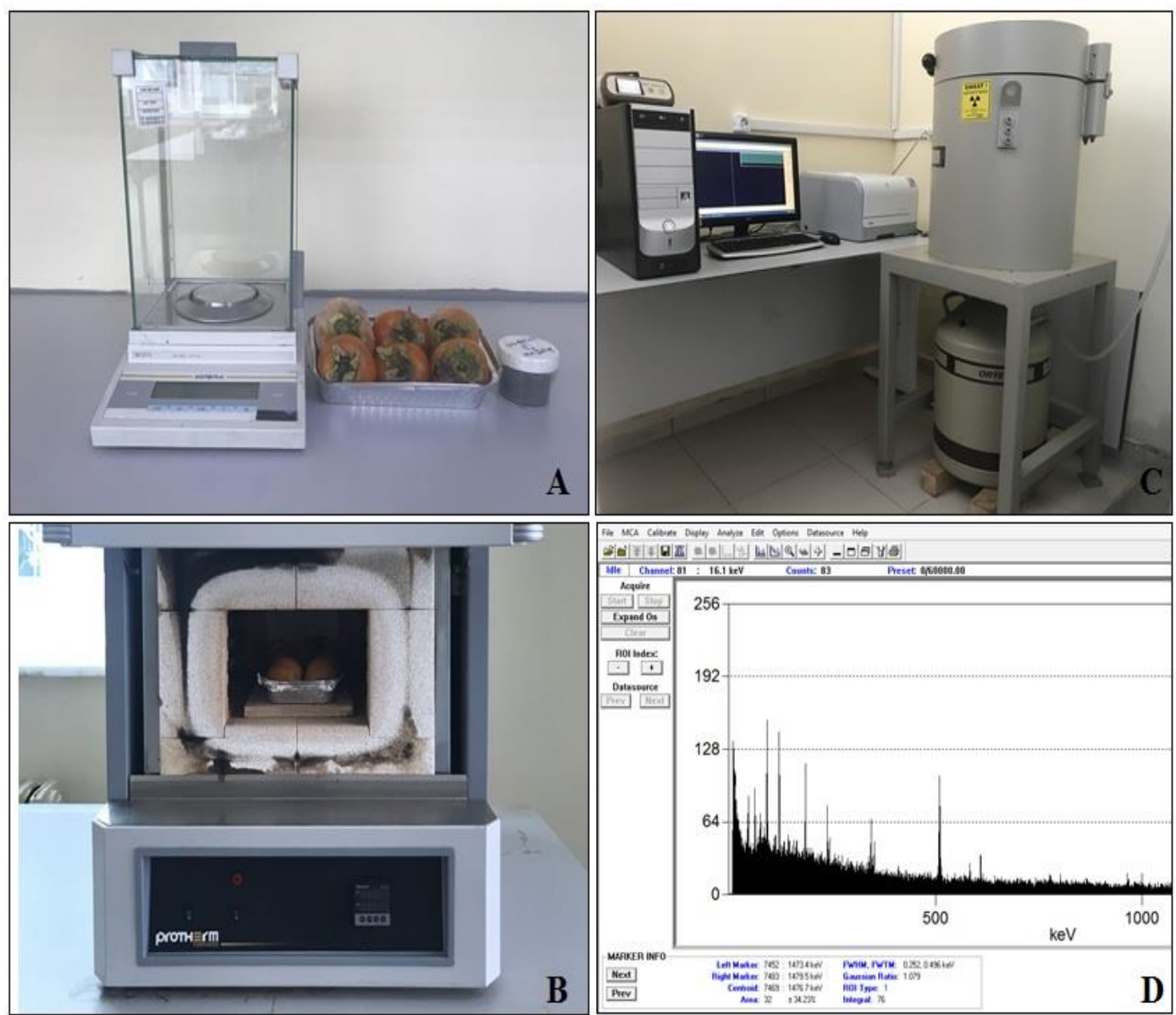

Şekil 2. A: Çalışmada kullanılan terazi B: Örneklerin kül hale getirilmesi için kullanılan fırın C:

Radyonüklitlerin aktivite konsantrasyonlarının belirlenmesi için kullanılan HPGe dedektör sistemi D:

Cennet hurması örneklerine ait bir spektrum

HPGe dedektörünün fotopik verimi, Evropyum-152 ( $\left.{ }^{152} \mathrm{Eu}\right)$ kaynağının 121.8, 244.5, $344.2,411.0,444.1,779.3,867.6$ ve $1408.4 \mathrm{keV}$ enerjilerindeki pikleri dikkate alınarak Denklem 1 yardımıyla hesaplanmıştır (Parmaksız, 2004). Denklem 1'de, $\varepsilon(E)$ : dedektörün ilgilenilen gama enerjisindeki fotopik verimini, $\mathrm{N}$ : $\mathrm{E}$ enerjili fotopikin altındaki net alanı (sayım), $P_{\gamma}(\%)$ : ilgilenilen bir $E$ enerjisindeki gama ışınının yayınlanma olasılığını, $\mathrm{A}_{0}:{ }^{152} \mathrm{Eu}$ kaynağının referans tarihindeki aktivitesini (bozunma/saniye), t: sayım süresini (saniye), $\lambda$ : bozunma sabitini, $t_{d}:{ }^{152} E u$ kaynağının referans tarihinden ölçme işlemi tarihine kadar geçen süreyi ifade etmektedir.

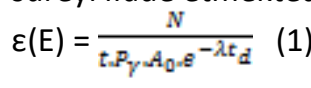

Her bir örnek 60.000 saniye sayım alınması için dedektöre yerleştirilmiş ve background (fon) ölçümleri aynı koşullar altında gerçekleştirilerek örneklerdeki gama konsantrasyonlarının net sayımlarının hesaplanmasında kullanılmıştır. Örneklerdeki ${ }^{238} \mathrm{U}$ aktivite konsantrasyonunun belirlenmesi için ${ }^{214} \mathrm{~Pb}$ radyoizotopunun $295.2 \mathrm{keV}$ ve 351.9 $\mathrm{keV}$ ile ${ }^{214} \mathrm{Bi}$ radyoizotopunun $609.3 \mathrm{keV}$ gama ışını enerjili piklerindeki aktivitelerin ortalaması ve ${ }^{232} \mathrm{Th}$ aktivite konsantrasyonunun belirlenmesi için ${ }^{228} \mathrm{Ac}$ radyoizotopunun 911.2 keV ve $968.9 \mathrm{keV}$ gama enerjili piklerindeki aktivitelerin ortalaması dikkate alınmıştır. ${ }^{137} \mathrm{Cs}$ ve ${ }^{40} \mathrm{~K}$ radyonüklitlerinin aktivitesini belirlemek için sırasıyla, $661.6 \mathrm{keV}$ ve $1460.8 \mathrm{keV}$ gama enerjisindeki piklerin alanlarından yararlanılmıştır. Radyonüklidlerin aktivite konsantrasyonlarını hesaplamak için Denklem 2 kullanılmıştır (Aswood ve ark., 2017).

Denklem 2'de $C_{n}$ : ilgilenilen $E$ enerjili gama fotopikinin altındaki net alanı (sayım), t: sayım süresini (saniye), $\varepsilon(E)$ : dedektörün 
ilgilenilen fotopikteki verimini, $\mathrm{P}_{\gamma}$ (\%): $\mathrm{E}$ enerjisindeki gama ışınının yayınlanma olasılığını ve $\mathrm{m}$ : numune kütlesini (kilogram) belirtmektedir.

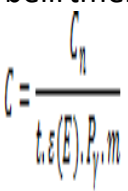

Her bir radyonüklit için dedektör sisteminin minimum dedekte edilebilir aktivite değerleri (mda) Denklem 3 kullanılarak hesaplanmıştır (Anonymous, 1989; Keser, 2009). Denklem 3'de, mda: ilgilenilen radyonüklit için minimum dedekte edilebilir aktiviteyi, B: doğal fon spektrumunda ilgilenilen radyonüklit piki için sayımı (alanı), t: sayım süresini, Py (\%): E enerjisindeki gama ışınının yayınlanma olasılığını, $\mathrm{m}$ : numune kütlesini ve $\varepsilon(E)$ : dedektörün ilgilenilen fotopikteki verimini ifade etmektedir.

$$
m d a=\frac{4.66 / B}{t_{1} P_{p} m,(B)}
$$

Çizelge 7'de aktivitesi ölçülen radyonüklitlerin bazı özellikleri belirtilmiştir. Çizelge 9 ve $10^{\prime}$ da minimum dedekte edilebilir aktivite değerlerinden daha düşük olan veriler tespit edilemedi (te) olarak ifade edilmiştir.

Çizelge 7. Aktivitesi ölçülen radyonüklitlerin bazı özellikleri (Al-Masri ve ark., 2007; Caciolli ve ark., 2019; Khandaker ve ark., 2016; Salih, 2019; Ying ve ark., 2015)

\begin{tabular}{|c|c|c|c|c|c|}
\hline Radyonüklit & $\begin{array}{l}\text { Bozunma } \\
\text { ürünü }\end{array}$ & $\begin{array}{l}\text { Gama ışını } \\
\text { enerjisi E } \\
\text { (keV) }\end{array}$ & $\begin{array}{c}\text { Yayınlanma } \\
\text { Olasılığı } \\
\text { Py (\%) }\end{array}$ & Verim $\varepsilon(E)$ & $\begin{array}{c}\text { Minimum } \\
\text { dedeksiyon } \\
\text { aktivitesi } \\
\left(\mathrm{Bq} \mathrm{kg}^{-1}\right)\end{array}$ \\
\hline \multirow{3}{*}{${ }^{238} \mathrm{U}$} & ${ }^{214} \mathrm{~Pb}$ & 295.2 & 18.2 & 0.0575 & 1.71 \\
\hline & ${ }^{214} \mathrm{~Pb}$ & 351.9 & 37.6 & 0.0510 & 1.10 \\
\hline & ${ }^{214} \mathrm{Bi}$ & 609.3 & 46.3 & 0.0349 & 1.15 \\
\hline \multirow{2}{*}{${ }^{232} \mathrm{Th}$} & ${ }^{228} \mathrm{Ac}$ & 911.2 & 25.8 & 0.0265 & 1.61 \\
\hline & ${ }^{228} \mathrm{Ac}$ & 968.9 & 15.8 & 0.0254 & 0.10 \\
\hline${ }^{137} \mathrm{Cs}$ & ${ }^{137} \mathrm{Cs}$ & 661.6 & 85.1 & 0.0330 & 0.00 \\
\hline${ }^{40} \mathrm{~K}$ & ${ }^{40} \mathrm{~K}$ & 1460.8 & 10.6 & 0.0191 & 9.66 \\
\hline
\end{tabular}

İnsanların

maddelerindeki

tükettikleri

gıda

radyonüklitlerden maruz kaldıkları radyasyon doz değerlerinin tespiti ve bu doz değerlerinin, uluslararası kuruluşlar tarafından belirlenen ortalama değerlere göre risk teşkil edip etmediğini belirlemek için yıllık etkin doz kavramı kullanılmaktadır. Yıllık etkin doz, bir yıllık süre içerisinde tüketilen gıda maddelerinden yayınlanan gama ışınlarına dahili olarak maruz kalmak suretiyle oluşabilecek radyasyon doz değeridir. Bu çalışmada Cennet hurması örneklerindeki ${ }^{238} \mathrm{U}$, ${ }^{232} \mathrm{Th},{ }^{137} \mathrm{Cs}$ ve ${ }^{40} \mathrm{~K}$ radyonüklitlerinden kaynaklanabilecek yıllık etkin doz değerleri Denklem 4 yardımıyla hesaplanmıştır (Harb, 2015; Nasreddine ve ark., 2008).

Denklem 4'te $H_{Y}$ : iç ışınlamadan kaynaklanabilecek yıllık etkin doz değerini ( $\mu S_{v}$ $\left.\mathrm{y}^{-1}\right), U_{\mathrm{r}}$ : bir yıllık tüketim miktarını $(\mathrm{kg}), C^{x}$ : ilgilenilen radyonüklitin aktivite konsantrasyonunu, $g_{r}$ : ilgilenilen radyonüklit için doz dönüşüm faktörünü ifade etmektedir. ${ }^{238} \mathrm{U}$ için doz dönüşüm faktörü $4.5 \times 10^{-8} \mathrm{~Sv} \mathrm{~Bq}^{-1}$, ${ }^{232} \mathrm{Th}$ için $2.3 \times 10^{-7} \mathrm{~Sv} \mathrm{~Bq}{ }^{-1},{ }^{137} \mathrm{Cs}$ için $1.3 \times 10^{-8} \mathrm{~Sv}$ $\mathrm{Bq}^{-1}$ ve ${ }^{40} \mathrm{~K}$ için $6.2 \times 10^{-9} \mathrm{~Sv} \mathrm{~Bq}^{-1}$ dir (Anonymous, 2012).

Çizelge 10 ve Çizelge $11^{\prime}$ de $\mathrm{H}_{\mathrm{U}-238}, \mathrm{H}_{\mathrm{Th}}$ 232, $\mathrm{H}_{\mathrm{cs}-137}$ ve $\mathrm{H}_{\mathrm{K}-40}$, sırası ile Cennet hurması örneklerindeki ${ }^{238} \mathrm{U},{ }^{232} \mathrm{Th},{ }^{137} \mathrm{Cs}$ ve ${ }^{40} \mathrm{~K}$ radyonüklitlerinden kaynaklanabilecek yıllık etkin doz değerlerini belirtmektedir, $\mathrm{H}_{\text {Toplam }}$ ise tüm bu radyonüklitlerden kaynaklanan toplam yıllık etkin doz değerlerini ifade etmektedir.

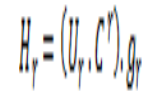<smiles>[CH]=C</smiles>

Cennet hurması meyvesinin, günlük beslenme alışkanlığı içerisinde tüketimi, $25 \mathrm{gr}$ gün ${ }^{-1}$ olarak önerilen günlük lif ihtiyacının karşılanması açısından önemlidir (Yücecan, 2008). Türkiye İstatistik Kurumu verilerine göre (Anonim, 2016b), Türkiye'de kişi başına tüketilen meyve miktarlarının yıllara göre 
değişimi Çizelge $8^{\prime}$ de belirtilmiştir. Çizelge 8'e göre 2016 yılında 20 farklı meyvenin kişi başına yıllık tüketim miktarları $0.5 \mathrm{~kg}$ ile $43.2 \mathrm{~kg}$ arasında değişiklik göstermiştir. Kişi başına yıllık tüketim miktarı en yüksek karpuz için ve en düşük incir için belirlenmiştir. 2016 yılında diğer meyvelerin yıllık kişi başına meyve tüketimindeki değeri ise $2.8 \mathrm{~kg}$ olarak tespit edilmiştir (Anonim, 2016b). Bu çalışmada yetişkin bir insan için bir yılda $2.8 \mathrm{~kg}$ Cennet hurması tüketmesi durumunda, temin edilen örneklerdeki radyonüklitlerin aktivite konsantrasyonları yardımıyla, yöre halkının ${ }^{238} \mathrm{U},{ }^{232} \mathrm{Th},{ }^{137} \mathrm{Cs}$ ve ${ }^{40} \mathrm{~K}$ radyonüklitlerinden maruz kalabilecekleri yıllık etkin doz değerleri hesaplanmıştır.

Çizelge 8. Türkiye'de kişi başına tüketilen meyve miktarlarının yıllara göre değişimi (Anonim, 2016b)

\begin{tabular}{|c|c|c|c|c|c|c|c|}
\hline \multirow[b]{2}{*}{ Meyveler } & \multicolumn{7}{|c|}{ Kişi başı tüketim miktarı (kg) } \\
\hline & 2010 & 2011 & 2012 & 2013 & 2014 & 2015 & 2016 \\
\hline Karpuz & 43.4 & 45.2 & 46.6 & 44.4 & 43.4 & 43.3 & 43.2 \\
\hline Üzüm & 34.4 & 34.8 & 31.6 & 32.7 & 29.8 & 26.3 & 28.7 \\
\hline Elma & 24.8 & 25.3 & 30 & 27.3 & 21.3 & 23 & 23.5 \\
\hline Kavun & 19.1 & 19.3 & 19.5 & 19.3 & 19.2 & 19 & 20.3 \\
\hline Portakal & 17.2 & 16.7 & 17.5 & 16.9 & 17.2 & 15.8 & 14.2 \\
\hline Mandalina & 5.1 & 4.9 & 5.7 & 5 & 5.2 & 6.9 & 7.3 \\
\hline Şeftali & 6.1 & 6.1 & 6.6 & 7 & 6.5 & 6.6 & 7 \\
\hline Muz & 5.4 & 5.2 & 5.4 & 5 & 5.5 & 5.6 & 5.9 \\
\hline Kiraz & 4.1 & 4.4 & 4.7 & 4.9 & 4.3 & 4.9 & 5.5 \\
\hline Armut & 4.3 & 4.4 & 4.9 & 5 & 4.9 & 4.8 & 4.9 \\
\hline Çilek & 3.2 & 3.2 & 3.8 & 4 & 4 & 3.9 & 4.3 \\
\hline Limon & 3.3 & 3.8 & 3.8 & 3.1 & 3.2 & 3.5 & 3.9 \\
\hline Nar & 1.7 & 1.8 & 2.6 & 2.7 & 2.9 & 3.1 & 3.3 \\
\hline Kayısı & 0.3 & 1.5 & 2.2 & 2.5 & 0.6 & 1.6 & 2.7 \\
\hline Erik & 2.5 & 2.6 & 2.8 & 2.8 & 2.4 & 2.3 & 2.4 \\
\hline Vişne & 2.3 & 2.1 & 2.2 & 2.1 & 2.1 & 2 & 2.1 \\
\hline Greyfurt & 0.7 & 0.4 & 1.1 & 0.6 & 0.9 & 0.6 & 1.4 \\
\hline Ayva & 1.3 & 1.4 & 1.4 & 1.4 & 1.1 & 1.1 & 1.2 \\
\hline Dut & 0.9 & 0.9 & 0.8 & 0.8 & 0.7 & 0.7 & 0.7 \\
\hline İncir & 0.2 & 0.3 & 0.2 & 0.2 & 0.5 & 0.6 & 0.5 \\
\hline Diğer meyveler & 2.6 & 2.7 & 2.9 & 3 & 2.5 & 2.6 & 2.8 \\
\hline
\end{tabular}

\section{Araştırma Bulguları ve Tartışma}

Bu çalışma kapsamında Rize ilindeki yedi ilçeden (İyidere, Derepazarı, Rize Merkez İlçe, Çayeli, Pazar, Ardeşen, Fındıklı) toplanan Cennet hurması örneklerindeki doğal $\left({ }^{238} \mathrm{U}\right.$, $\left.{ }^{232} \mathrm{Th},{ }^{40} \mathrm{~K}\right)$ ve yapay $\left({ }^{137} \mathrm{Cs}\right)$ radyonüklitlerin aktivite konsantrasyonları Çizelge 9'da gösterilmiştir. 
Çizelge 9. Cennet hurması örneklerindeki doğal $\left({ }^{238} \mathrm{U},{ }^{232} \mathrm{Th},{ }^{40} \mathrm{~K}\right)$ ve yapay $\left({ }^{137} \mathrm{Cs}\right)$ radyonüklitlerin aktivite konsantrasyonları $\left(\mathrm{Bq} \mathrm{kg}^{-1}\right)$

\begin{tabular}{llccccc}
\hline No & illçe & İstasyon & ${ }^{238} \mathrm{U}$ & ${ }^{232} \mathrm{Th}$ & ${ }^{137} \mathrm{Cs}$ & ${ }^{40} \mathrm{~K}$ \\
\hline S1 & Denizgören & $4.59 \pm 0.49$ & $3.16 \pm 0.51$ & $2.10 \pm 0.39$ & $1382.82 \pm 21.57$ \\
S2 & İyidere & Fıçıtaşı & $3.15 \pm 0.29$ & te & $7.78 \pm 0.38$ & $1346.54 \pm 14.95$ \\
S3 & & Sarayköy & $5.87 \pm 0.55$ & $2.71 \pm 0.57$ & te & $1137.35 \pm 17.63$ \\
S4 & & Fıçıcılar & te & te & te & $1234.29 \pm 21.72$ \\
S5 & Derepazarı & Sayıyer & $5.48 \pm 0.56$ & $5.75 \pm 0.87$ & te & $1684.01 \pm 26.61$ \\
S6 & & Bürücek & $7.66 \pm 0.75$ & $10.29 \pm 1.45$ & $4.99 \pm 0.53$ & $1903.27 \pm 29.52$ \\
S7 & \multirow{2}{*}{ Merkez } & Kendirli & $3.18 \pm 0.39$ & $10.91 \pm 1.78$ & $29.24 \pm 1.15$ & $2160.07 \pm 33.70$ \\
S8 & İlçe & Fener & te & te & $6.09 \pm 0.54$ & $1086.04 \pm 19.70$ \\
S9 & Veliköy & $3.16 \pm 0.37$ & te & $14.63 \pm 0.70$ & $1441.92 \pm 22.93$ \\
S10 & & Limanköy & $2.82 \pm 0.29$ & $3.06 \pm 0.56$ & $2.35 \pm 0.35$ & $954.11 \pm 16.51$ \\
S11 & Çayeli & Büyükköy & $2.43 \pm 0.33$ & $8.65 \pm 1.22$ & $10.04 \pm 0.70$ & $1658.79 \pm 26.87$ \\
S12 & & Kesmetaş & te & $6.60 \pm 1.30$ & $2.08 \pm 0.28$ & $1118.00 \pm 14.43$ \\
S13 & Hisarlı & $4.36 \pm 0.46$ & $3.63 \pm 0.35$ & $2.87 \pm 0.39$ & $1393.55 \pm 20.90$ \\
S14 & Pazar & Kirazlık M. & $4.89 \pm 0.44$ & $9.22 \pm 1.22$ & $3.02 \pm 0.49$ & $1607.34 \pm 22.82$ \\
S15 & Hamidiye & $5.34 \pm 0.59$ & $4.93 \pm 0.84$ & $14.28 \pm 0.72$ & $1503.26 \pm 22.55$ \\
S16 & Gazi Cd. & te & $2.36 \pm 0.42$ & $46.78 \pm 0.83$ & $863.62 \pm 12.52$ \\
S17 & Ardeşen & Pirinçlik & $3.63 \pm 0.45$ & te & $30.97 \pm 1.20$ & $2278.29 \pm 33.49$ \\
S18 & & Işıklı & te & $2.29 \pm 0.48$ & $85.03 \pm 1.07$ & $901.51 \pm 12.71$ \\
S19 & Yeniköy & $5.21 \pm 0.59$ & $9.02 \pm 1.55$ & $45.09 \pm 1.42$ & $1722.18 \pm 29.45$ \\
S20 & Fındıklı & Sahil & te & $2.36 \pm 0.42$ & $29.04 \pm 0.72$ & $935.57 \pm 13.94$ \\
S21 & Dereüstü & $13.47 \pm 0.62$ & $9.14 \pm 1.41$ & $46.14 \pm 1.45$ & $1899.91 \pm 30.40$ \\
\hline Minimum & & $2.43 \pm 0.33$ & $2.29 \pm 0.48$ & $2.08 \pm 0.28$ & $863.62 \pm 12.52$ \\
Maksimum & & $13.47 \pm 0.62$ & $10.91 \pm 1.78$ & $85.03 \pm 1.07$ & $2278.29 \pm 33.49$ \\
Ortalama & & $5.01 \pm 0.48$ & $5.87 \pm 0.93$ & $21.25 \pm 0.74$ & $1438.69 \pm 22.14$ \\
\hline
\end{tabular}

*te: tespit edilemedi

Çizelge 9 incelendiğinde, Cennet hurması örneklerinde tespit edilen en düşük radyasyon aktivite konsantrasyonları ${ }^{238} \mathrm{U}$ için $2.43 \pm 0.33 \mathrm{~Bq} \mathrm{~kg}{ }^{-1}$ olarak Çayeli Büyükköy (S11) istasyonunda, ${ }^{232} \mathrm{Th}$ için $2.29 \pm 0.48 \mathrm{~Bq} \mathrm{~kg}^{-1}$ olarak Ardeşen Işıklı (S18) istasyonunda ve ${ }^{137} \mathrm{Cs}$ için $2.08 \pm 0.28 \mathrm{~Bq} \mathrm{~kg}{ }^{-1}$ olarak Çayeli Kesmetaş (S12) istasyonunda ölçülmüştür. İyidere Sarayköy (S3), Derepazarı Fıçıcılar (S4) ve Derepazarı Sayıyer (S5) istasyonlarında ${ }^{137} \mathrm{Cs}$ aktivitesine rastlanmazken, Derepazarı Fıçıcılar (S4) ve Rize Merkez İlçe Fener (S8) istasyonlarında hem ${ }^{238} \mathrm{U}$ hem de ${ }^{232} \mathrm{Th}$ aktivite konsantrasyonları dedeksiyon limitlerinin altında olduğu için tespit edilememiştir. Bununla birlikte Çayeli Kesmetaş (S12), Ardeşen Gazi Cd. (S16), Ardeşen Işıklı (S18) ve Fındıklı Sahil (S20) istasyonlarındaki örneklerde ${ }^{238} \mathrm{U}$ aktivite konsantrasyonunun, İyidere Fıçıtaşı (S2), Rize Merkez İlçe Veliköy (S9) ve Ardeşen Pirinçlik (S17) istasyonlarındaki örneklerde ${ }^{232}$ Th aktivite konsantrasyonunun dedeksiyon limitlerinin altıda olduğu ve tespit edilemedikleri görülmektedir.
Çizelge 9'daki verilere göre en yüksek radyasyon aktivite konsantrasyonları ${ }^{238} \mathrm{U}$ için $13.47 \pm 0.62 \mathrm{~Bq} \mathrm{~kg}{ }^{-1}$ olarak Fındıklı Dereüstü (S21) istasyonunda, ${ }^{232} \mathrm{Th}$ için $10.91 \pm 1.78 \mathrm{~Bq} \mathrm{~kg}$ 1 olarak Rize Merkez illçe Kendirli (S7) istasyonunda ve ${ }^{137} \mathrm{Cs}$ için $85.03 \pm 1.07 \mathrm{~Bq} \mathrm{~kg}^{-1}$ olarak Ardeşen Işıklı (S18) istasyonunda tespit edilmiştir. İstasyonlardaki ${ }^{40} \mathrm{~K}$ aktivite konsantrasyonu en düşük değeri Ardeşen Gazi Cd. istasyonunda (S16) $863.62 \pm 12.52 \mathrm{~Bq} \mathrm{~kg}{ }^{-1}$ olarak ve en yüksek değeri Ardeşen Pirinçlik (S17) istasyonunda 2278.29 $\pm 33.49 \mathrm{~Bq} \mathrm{~kg}$ kg $^{-1}$ olarak almıştır.

Çizelge 9'da örneklerde hesaplanan ortalama ${ }^{238} \mathrm{U},{ }^{232} \mathrm{Th},{ }^{137} \mathrm{Cs}$ ve ${ }^{40} \mathrm{~K}$ aktivite konsantrasyonları sırasıyla $5.01 \pm 0.48 \mathrm{~Bq} \mathrm{~kg}{ }^{-1}$, $5.87 \pm 0.93 \mathrm{~Bq} \mathrm{~kg}$, $21.25 \pm 0.74 \mathrm{~Bq} \mathrm{~kg}{ }^{-1}$ ve $1438.69 \pm 22.14 \mathrm{~Bq} \mathrm{~kg}{ }^{-1}$ olarak bulunmuştur. Uluslararası Radyolojik Korunma Komitesi (ICRP)'ne göre tüketilen gıda maddeleri için izin verilen ${ }^{137} \mathrm{Cs}$ aktivite konsantrasyonunun limit değeri $1000 \mathrm{~Bq} \mathrm{~kg}{ }^{-1}$ olup (Anonymous, 2004c), bu çalışmadaki istasyonlardan temin edilen Cennet hurması örneklerinde tespit edilen ${ }^{137} \mathrm{Cs}$ aktivite konsantrasyonlarının $1000 \mathrm{~Bq} \mathrm{~kg}^{-1}$ limit 
değerinden oldukça düşük olduğu ve halk sağlığını tehdit edecek düzeyde olmadığı gözlenmiştir.

$\mathrm{Bu}$ çalışmada, istasyonlardan toplanan Cennet hurması örneklerinin insan sağlığı açısından risk teşkil edip etmediğini değerlendirebilmek için yıllık etkin doz değerleri hesaplanmıştır. Çizelge $10^{\prime}$ da Cennet hurması örneklerindeki ${ }^{238} \mathrm{U},{ }^{232} \mathrm{Th},{ }^{137} \mathrm{Cs}$ ve ${ }^{40} \mathrm{~K}$ radyonüklitlerinden kaynaklanan yıllık etkin doz değerleri verilmiştir.

Çizelge $10^{\prime} \mathrm{da}{ }^{238} \mathrm{U},{ }^{232} \mathrm{Th}$ ve ${ }^{137} \mathrm{Cs}^{\prime} \mathrm{dan}$ kaynaklanan en yüksek yıllık etkin doz değerlerinin sırasıyla ${ }^{238} \mathrm{U}$ için Fındıklı Dereüstü (S21) istasyonunda $1.697 \mu \mathrm{Sv} \mathrm{y}^{-1},{ }^{232} \mathrm{Th}$ için Rize Merkez illçe Kendirli (S7) istasyonunda 7.026 $\mu S v y^{-1}$ ve ${ }^{137} C s$ için Ardeşen Işıklı (S18) istasyonunda $\quad 3.095 \mu \mathrm{Sv} \quad \mathrm{y}^{-1}$ olduğu görülmektedir. ${ }^{238} \mathrm{U},{ }^{232} \mathrm{Th}$ ve ${ }^{137} \mathrm{Cs}$ için ortalama yıllık etkin doz değerleri sırasıyla ${ }^{238} \mathrm{U}$ için 0.632 $\mu S v y^{-1},{ }^{232}$ Th için $3.787 \mu S v y^{-1}$ ve ${ }^{137} C s$ için $0.774 \mu \mathrm{Sv} \mathrm{y}^{-1}$ olarak hesaplanmıştır.

Çizelge $10^{\prime} \mathrm{da}{ }^{238} \mathrm{U},{ }^{232} \mathrm{Th},{ }^{137} \mathrm{Cs}$ ve ${ }^{40} \mathrm{~K}$ radyonüklitlerinden kaynaklanan toplam yıllık etkin doz değeri en düşük Ardeşen Gazi Cd. (S16) istasyonunda $18.215 \mu \mathrm{Sv} \mathrm{y}^{-1}$ ve en yüksek Merkez İlçe Kendirli (S7) istasyonunda 45.990 $\mu \mathrm{Sv} \mathrm{y}^{-1}$ olarak tespit edilmiştir. İstasyonlardaki toplam yıllık etkin doz değerlerinin ortalaması ise $28.975 \mu \mathrm{Sv} \mathrm{y}^{-1}$ olarak hesaplanmıştır.

Çizelge 10'dan açıkça görüldüğü üzere toplam yıllık etkin doz değerine en yüksek katkı ${ }^{40} \mathrm{~K}$ radyonüklitinden gelmektedir. ${ }^{40} \mathrm{~K}$ radyonüklitinden kaynaklanan yıllık etkin doz değeri en düşük Ardeşen Gazi Cd. (S16) istasyonunda $14.992 \mu S v y^{-1}$ ve en yüksek Ardeşen Pirinçlik (S17) istasyonunda $39.551 \mu \mathrm{Sv}$ $\mathrm{y}^{-1}$ olarak tespit edilmiştir. ${ }^{40} \mathrm{~K}$ 'dan kaynaklanan yıllık etkin doz değerinin ortalaması ise 24.976 $\mu S v y^{-1}$ olarak hesaplanmıştır.

Çizelge 10. Cennet hurması örneklerindeki ${ }^{238} \mathrm{U},{ }^{232} \mathrm{Th},{ }^{137} \mathrm{Cs}$ ve ${ }^{40} \mathrm{~K}$ radyonüklitlerinden kaynaklanan yıllık etkin doz değerleri $\left(\mu \mathrm{Sv} \mathrm{y}^{-1}\right)$

\begin{tabular}{|c|c|c|c|c|c|c|c|}
\hline No & illçe & İstasyon & $\mathrm{Hu}-238$ & $\mathrm{H}_{\text {Th-232 }}$ & $\mathrm{H}_{\mathrm{cs}-137}$ & $\mathrm{H}_{\mathrm{K}-40}$ & $\mathrm{H}_{\text {Toplam }}$ \\
\hline S1 & \multirow{4}{*}{ İyidere } & Denizgören & 0.578 & 2.035 & 0.076 & 24.006 & 26.696 \\
\hline S2 & & Fıçıtaşı & 0.397 & te & 0.283 & 23.376 & 24.056 \\
\hline S3 & & Sarayköy & 0.740 & 1.745 & te & 19.744 & 22.229 \\
\hline S4 & & Fıçıcılar & te & te & te & 21.427 & 21.427 \\
\hline S5 & \multirow[t]{2}{*}{ Derepazarı } & Sayıyer & 0.690 & 3.703 & te & 29.234 & 33.628 \\
\hline S6 & & Bürücek & 0.965 & 6.627 & 0.182 & 33.041 & 40.814 \\
\hline S7 & \multirow{3}{*}{$\begin{array}{l}\text { Merkez } \\
\text { İlçe }\end{array}$} & Kendirli & 0.401 & 7.026 & 1.064 & 37.499 & 45.990 \\
\hline S8 & & Fener & te & te & 0.222 & 18.854 & 19.075 \\
\hline S9 & & Veliköy & 0.398 & te & 0.533 & 25.032 & 25.962 \\
\hline S10 & \multirow{4}{*}{ Çayeli } & Limanköy & 0.355 & 1.971 & 0.086 & 16.563 & 18.975 \\
\hline S11 & & Büyükköy & 0.306 & 5.571 & 0.365 & 28.797 & 35.039 \\
\hline S12 & & Kesmetaş & te & 4.250 & 0.076 & 19.408 & 23.735 \\
\hline S13 & & Hisarlı & 0.549 & 2.338 & 0.104 & 24.192 & 27.184 \\
\hline S14 & \multirow[t]{3}{*}{ Pazar } & Kirazlık M. & 0.616 & 5.938 & 0.110 & 27.903 & 34.567 \\
\hline S15 & & Hamidiye & 0.673 & 3.175 & 0.520 & 26.097 & 30.464 \\
\hline S16 & & Gazi Cd. & te & 1.520 & 1.703 & 14.992 & 18.215 \\
\hline S17 & \multirow[t]{3}{*}{ Ardeşen } & Pirinçlik & 0.457 & te & 1.127 & 39.551 & 41.136 \\
\hline S18 & & Işıklı & te & 1.475 & 3.095 & 15.650 & 20.220 \\
\hline S19 & & Yeniköy & 0.656 & 5.809 & 1.641 & 29.897 & 38.004 \\
\hline S20 & \multirow[t]{2}{*}{ Fındıklı } & Sahil & te & 1.520 & 1.057 & 16.241 & 18.818 \\
\hline S21 & & Dereüstü & 1.697 & 5.886 & 1.679 & 32.982 & 42.245 \\
\hline \multicolumn{2}{|c|}{ Minimum } & & 0.306 & 1.475 & 0.076 & 14.992 & 18.215 \\
\hline \multicolumn{2}{|c|}{ Maksimum } & & 1.697 & 7.026 & 3.095 & 39.551 & 45.990 \\
\hline \multicolumn{2}{|c|}{ Ortalama } & & 0.632 & 3.787 & 0.774 & 24.976 & 28.975 \\
\hline
\end{tabular}

*te: tespit edilemedi

Çizelge $11^{\prime}$ de Cennet hurması örneklerindeki ${ }^{238} \mathrm{U},{ }^{232} \mathrm{Th},{ }^{137} \mathrm{Cs}$ ve ${ }^{40} \mathrm{~K}$ radyonüklitlerinden kaynaklanan yıllık etkin doz değerlerinin ilçelere göre ortalaması, Şekil 3'de ise bu verilerin grafiği verilmiştir. Çizelge 11 ve
Şekil 3 incelendiğinde örneklerdeki en düşük ortalama yıllık etkin doz değeri ${ }^{238} \mathrm{U}$ için 0.330 $\mu S v y^{-1},{ }^{137} \mathrm{Cs}$ için $0.175 \mu S v \mathrm{y}^{-1}$ ve ${ }^{40} \mathrm{~K}$ için 21.589 $\mu \mathrm{Sv} \mathrm{y}^{-1}$ olarak Çayeli ilçesinde, ${ }^{232}$ Th için 1.497 $\mu \mathrm{Sv} \mathrm{y}^{-1}$ olarak Ardeşen ilçesinde olduğu, en 
yüksek ortalama yıllık etkin doz değerinin ${ }^{238} \mathrm{U}$ için Fındıklı ilçesinde $1.176 \mu \mathrm{Sv} \mathrm{y}^{-1},{ }^{232} \mathrm{Th}$ için Rize Merkez Illçede $7.026 \mu S v y^{-1},{ }^{137} \mathrm{Cs}$ için Ardeşen ilçesinde $1.975 \mu \mathrm{Sv} \mathrm{y}^{-1}$ ve ${ }^{40} \mathrm{~K}$ için Derepazarı ilçesinde $27.902 \mu \mathrm{Sv} \quad \mathrm{y}^{-1}$ olduğu tespit edilmiştir. ${ }^{238} \mathrm{U},{ }^{232} \mathrm{Th},{ }^{137} \mathrm{Cs}$ ve ${ }^{40} \mathrm{~K}$ radyonüklitlerinden kaynaklanan toplam yıllık etkin doz değerlerinin ilçelere göre ortalaması dikkate alındığında en düşük toplam yıllık etkin doz değerinin İyidere ilçesinde $24.327 \mu S v y^{-1}$ ve en yüksek toplam yıllık etkin doz değerinin Fındıklı ilçesinde $33.022 \mu \mathrm{Sv} \quad \mathrm{y}^{-1}$ olduğu görülmektedir.

$\mathrm{Bu}$ çalışmada, Cennet hurması örneklerindeki ${ }^{238} \mathrm{U}$ ve ${ }^{232} \mathrm{Th}$ radyonüklitlerinden olan katkının, Birleşmiş Milletler Atomik Radyasyonun Etkileri Bilimsel Komitesi (UNSCEAR) tarafından belirtilen dünya genelinde gida numunelerindeki ${ }^{238} \mathrm{U}$ ve ${ }^{232} \mathrm{Th}$ serisi radyonüklitlerin oluşturduğu ortalama yıllık etkin doz değeri olan 0.12 mSv (120 $\mu S v)$ 'den düşük olduğu, aynı şekilde ${ }^{40} K^{\prime}$ dan olan katkının Birleşmiş Milletler Atomik Radyasyonun Etkileri Bilimsel Komitesi (UNSCEAR) tarafından belirtilen dünya genelinde gıda numunelerindeki ${ }^{40} \mathrm{~K}^{\prime}$ dan oluşan ortalama yıllık etkin doz değeri olan $0.17 \mathrm{mSv}$ (170 $\mu S v)^{\prime}$ den düşük olduğu görülmektedir (Anonymous, 2000). Ayrıca örneklerdeki ${ }^{238} \mathrm{U}$, ${ }^{232} \mathrm{Th},{ }^{137} \mathrm{Cs}$ ve ${ }^{40} \mathrm{~K}$ 'radyonüklitleri tarafından kaynaklanan toplam yıllık etkin doz değerleri Birleşmiş Milletler Atomik Radyasyonun Etkileri Bilimsel Komitesi (UNSCEAR) tarafından belirtilen gıda yoluyla insanların doğal radyasyon kaynaklarına dahili olarak maruz kaldıkları yıllık ortalama radyasyon dozu olan $0.29 \mathrm{mSv}(290 \mu \mathrm{Sv})$ değerinin oldukça altındadır (Anonymous, 2000).

Çizelge 11. Cennet hurması örneklerindeki ${ }^{238} \mathrm{U},{ }^{232} \mathrm{Th},{ }^{137} \mathrm{Cs}$ ve ${ }^{40} \mathrm{~K}$ radyonüklitlerinden kaynaklanan yıllık etkin doz değerlerinin ilçelere göre ortalaması $\left(\mu \mathrm{Sv} \mathrm{y}^{-1}\right)$

\begin{tabular}{llllll}
\hline İlçe & $\mathrm{Hu}_{\mathrm{u}-238}$ & $\mathrm{H}_{\text {Th-232 }}$ & $\mathrm{H}_{\mathrm{cs}-137}$ & $\mathrm{H}_{\mathrm{K}-40}$ & $\mathrm{H}_{\text {Toplam }}$ \\
İyidere & 0.571 & 1.890 & 0.179 & 22.374 & 24.327 \\
Derepazarı & 0.827 & 5.165 & 0.182 & 27.902 & 31.956 \\
Merkez İlçe & 0.399 & 7.026 & 0.606 & 27.129 & 30.342 \\
Çayeli & 0.330 & 3.930 & 0.175 & 21.589 & 25.916 \\
Pazar & 0.612 & 3.817 & 0.244 & 26.064 & 30.738 \\
Ardeşen & 0.457 & 1.497 & 1.975 & 23.397 & 26.523 \\
Fındıklı & 1.176 & 4.405 & 1.459 & 26.373 & 33.022 \\
Minimum & 0.330 & 1.497 & 0.175 & 21.589 & 24.327 \\
Maksimum & 1.176 & 7.026 & 1.975 & 27.902 & 33.022 \\
Ortalama & 0.624 & 3.961 & 0.688 & 24.976 & 28.975 \\
\hline
\end{tabular}

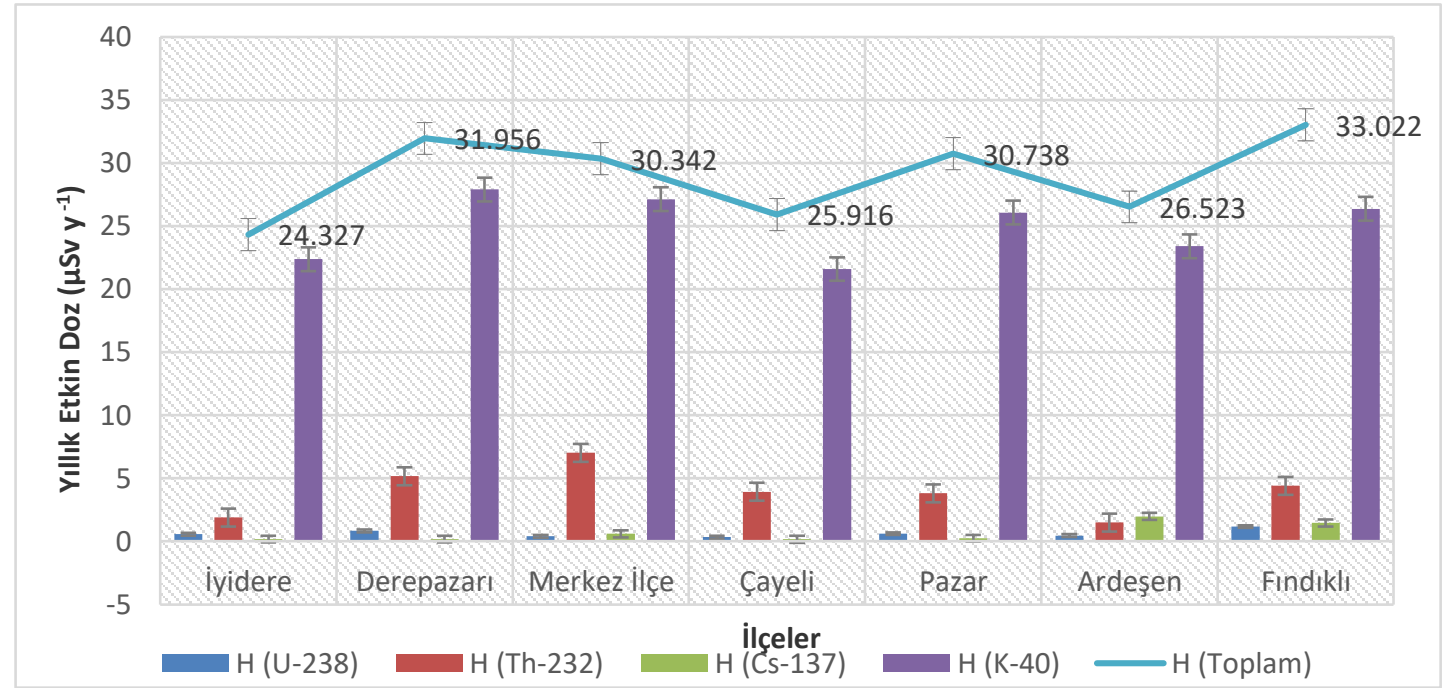

Şekil 3. Cennet hurması örneklerindeki ${ }^{238} \mathrm{U},{ }^{232} \mathrm{Th},{ }^{137} \mathrm{Cs}$ ve ${ }^{40} \mathrm{~K}$ radyonüklitlerinden kaynaklanan yıllık etkin doz değerlerinin ilçelere göre ortalamalarının grafiği 


\section{Sonuç}

$\mathrm{Bu}$ çalışmada Cennet hurması üretiminde önemli bir kapasiteye sahip olan Rize ilinden temin edilen Cennet hurması örneklerinde doğal ve yapay radyoüklitlerin aktivite konsantrasyonları ve bu radyonüklitlerin oluşturduğu yıllık etkin doz değerleri hesaplanmıştır. Elde edilen veriler neticesinde istasyonlardaki ${ }^{238} \mathrm{U},{ }^{232} \mathrm{Th},{ }^{137} \mathrm{Cs}$ ve ${ }^{40} \mathrm{~K}$ aktivite konsantrasyonlarının ortalaması sırasıyla $5.01 \pm 0.48 \mathrm{~Bq} \mathrm{~kg}{ }^{-1}, 5.87 \pm 0.93 \mathrm{~Bq} \mathrm{~kg}^{-1}$, $21.25 \pm 0.74 \mathrm{~Bq} \mathrm{~kg}{ }^{-1}$ ve $1438.69 \pm 22.14 \mathrm{~Bq} \mathrm{~kg}^{-1}$ olarak bulunmuştur ve aynı radyonüklitlerden kaynaklanan toplam yıllık etkin doz değerleri 18.215 $\mu \mathrm{Sv} \mathrm{y}^{-1}$ ile $45.990 \mu \mathrm{Sv} \mathrm{y}^{-1}$ aralığında tespit edilmiştir. Örneklerdeki ${ }^{137} \mathrm{Cs}$ aktivitelerinin, Uluslararası Radyolojik Korunma Komitesi (ICRP) tarafından gıda numunelerindeki ${ }^{137} \mathrm{Cs}$ aktivite konsantrasyonu için belirlenen $1000 \mathrm{~Bq} \mathrm{~kg}{ }^{-1}$ limit değerinden düşük olduğu ve toplam yıllık etkin doz değerlerinin Birleşmiş Milletler Atomik Radyasyonun Etkileri Bilimsel Komitesi (UNSCEAR) tarafından belirtilen insanların gıda yoluyla tüm doğal radyoaktif kaynaklardan dahili olarak maruz kaldıkları yıllık ortalama radyasyon dozu olan $0.29 \mathrm{mSv}(290 \mu \mathrm{Sv})$ değerinin oldukça altında olduğu sonucuna varılmıştır (Anonymous, 2000; Anonymous, 2004c). Bu çalışma neticesinde bu örnekleri tüketen insanların ve Cennet hurması örneklerinin toplandığı istasyonlardaki halkın sağlık açısından herhangi bir radyasyon riski altında kalmadığı söylenebilmektedir. Bu çalışma, Cennet hurması örneklerinde doğal $\left({ }^{238} \mathrm{U}, \quad{ }^{232} \mathrm{Th}, \quad{ }^{40} \mathrm{~K}\right)$ ve yapay $\left({ }^{137} \mathrm{Cs}\right)$ radyonüklitlerden kaynaklanan radyasyon aktivite konsantrasyonlarının ve yıllık etkin doz değerlerinin belirlendiği öncü çalışmalardan biri olup daha sonraki zamanlarda ülkemizde ve diğer ülkelerde yapılabilecek çalışmalara katkı sağlayacak temel bir veri niteliğindedir.

\section{Kaynaklar}

Anonim. 2016a. Türkiye İstatistik Kurumu Bitkisel Üretim İstatistikleri. www.tuik.gov.tr (Erişim tarihi: 14. 05. 2020)

Anonim. 2016b. Türkiye İstatistik Kurumu Bitkisel Ürün Denge Tabloları. www.tuik.gov.tr (Erişim tarihi: 14. 05. 2020)

Anonim. 2017. Türkiye İstatistik Kurumu Bitkisel Üretim İstatistikleri. www.tuik.gov.tr (Erişim tarihi: 10.07.2017).
Anonim. 2019. T.C. Tarım ve Orman Bakanlığı, Rize II Tarım ve Orman Müdürlüğü. (https://rize.tarimorman.gov.tr (Erişim tarihi: 12.08.2019).

Anonymous. 1989. International Atomic Energy Agency, 1989. Measurement of Radionuclides in Food and Environment, Technical Reports Series No: 295.

Anonymous. 2000. United Nations Scientific Committee on the Effects of Atomic Radiation. Sources and Effects of lonizing Radiation, UNSCEAR 2000 Report to the General Assembly, with Scientific Annexes Volume I: Sources, Annex B: Exposures From Natural Radiation Sources, United Nations, New York.

Anonymous. 2003. Chernobyl: assessment of radiological and health impacts. 2002 Update of Chernobyl: ten years on. Paris: Nuclear Energy Agency of the Organization for Economic Cooperation and Development, 2003.

Anonymous. 2004a. Agency for Toxic Substances and Disease Registry. Toxicological Profile for Cesium, Atlanta, Georgia.

Anonymous. 2004b. International Atomic Energy Agency, 2004. Division of Public Information, Report No: INISXA703, Radiation, people and the environment, Ford, J. (Ed.), Austria, Vienna.

Anonymous. 2004c. International Commission on Radiological Protection, 2004. Protecting people against radiation exposure in the aftermath of a radiological attack. Final TG draft.

Anonymous. 2008. Poptop Transplantable Photon Detector User Manual, Ortec Advanced Measurement Technology Inc., USA.

Anonymous. 2012. Compendium of Dose Coefficients based on ICRP Publication 60. ICRP Publication 119. Ann. ICRP 41(Suppl.).

Anonymous. 2017. Food and Agriculture Organization of the United Nations. http://www.fao.org/faostat/en/\#data/ QC (Erişim tarihi: 28. 06. 2017).

Aktepe Tangu, N., Erenoğlu, B. ve Yalçınkaya, E. 2010. Bazı Trabzon hurması çeşitlerinin Yalova ekolojisindeki performansları. Bahçe, 39(2), 1-8. 
Al-Masri, S.M. and Abdul-aziz, A. 2007. First proficiency test for the determination of NORM in contaminated soil from the oil field. Accreditation and Quality Assurance, 12, 249-256.

Aswood, M.S., Jaafar, M.S., and Salih, N. 2017. Estimation of annual effective dose due to natural radioactivity in ingestion of vegetables from Cameron Highlands, Malaysia. Environmental Technology \& Innovation, 8, 96-102.

Butt, M.S., Sultan, M.T., Aziz, M., Naz, A., Ahmed, W., Kumar, N. and Imran, M. 2015. Persimmon (Diospyros kaki) fruit: hidden phytochemicals and health claims. EXCLI Journal, 4 (14): 542-561.

Caciolli, A. Depalo, R. and Rigato, V. 2019. A new study of the $10 B(p, \$ \backslash$ alpha_\{1\}\gamma\$ $\alpha 1 \gamma) 7 B e$ reaction from 0.35 to $1.8 \mathrm{MeV}$. The European Physical Journal A, 55, 1-6.

Çalışkan, G. ve Dirim, S.N. 2015. Freeze drying kinetics of Persimmon puree. Gıda, 40 (1): 9-14

Harb, S. 2015. Natural radioactivity concentration and annual effective dose in selected vegetables and fruits. Journal of Nuclear and Particle Physics, 5(3): 70-73.

Jackson, D. 1986. The persimmon. "Alınmıştır: Temperate and subtropical fruit production. (ed) Monselise, S.P.. Butterworth, Wellington, New Zealand.

Kaplankıran, M. 2011. Subtropik Meyveler II (Ders Notları). Mustafa Kemal Üniversitesi Ziraat Fakültesi Bahçe Bitkileri Bölümü, Hatay (Yayımlanmamış).

Karaaslan, S. 2014. Trabzon Hurmasının mikrodalga ile kurutulmasında uygun kuruma modelinin belirlenmesi. Süleyman Demirel Üniversitesi Ziraat Fakültesi Dergisi, 9 (1): 8-15.

Keser, R. 2009. Rize Ili Sahil Kumlarında ve Bazı Kayaçlarda Doğal Gama Radyoaktivite Seviyelerinin Belirlenmesi, Karadeniz Teknik Üniversitesi, Fen Bilimleri Enstitüsü, Doktora Tezi, Trabzon, $162 \mathrm{~s}$.

Khandaker, M.U., Mohd Nasir N.L., Asaduzzaman, K., Olatunji, M.A., Mohd Amin, Y., Abu Kassim, H., Bradley, D.A., Jojo, P.J. and Alrefae, T. 2016. Evaluation of radionuclides transfer from soil-to-edible flora and estimation of radiological dose to the Malaysian populace. Chemosphere, 154, 528-536.

Kuzucu, F.C., 2003. Çanakkale-Lapseki Koşullarında Yetiştirilen Trabzon Hurmalarında Meyve Gelişimi, Olgunlaşma ve Depolama Karakteristikleri Üzerinde Araştırmalar. Trakya Üniversitesi, Tekirdağ Ziraat Fakültesi, Bahçe Bitkileri Anabilim Dalı, Doktora Tezi, Tekirdağ, $171 \mathrm{~s}$.

Nasreddine, L., El Samad, O., Hwalla, N., Baydoun, R., Hamze M. and ParentMassin, D. 2008. Activity concentrations and mean annual effective dose from gamma emitting radionuclides in the Lebanese diet. Radiation Protection Dosimetry, 131(4), 545-550.

Onur, S. 1990. Trabzon hurması. Derim, 7 (1): 447.

Onur, S. 1985. Trabzon hurması. Derim, 2 (2): 38-42.

Onur, C. ve Onur, S. 1997. Karadeniz Bölgesi Trabzon hurması (Diospyros kaki L.) Seleksiyonu. Derim, 14 (4): 146-156.

Öz, A.T. ve Özelkök, İ.S. 2003. "Moralı” Trabzon hurması (Diospyros kaki L.) meyvesinin burukluğunun giderilmesinde kuru buz uygulamasının etkisi. Bahçe, 32 (1-2): 713.

Özcan, M. 2018. Türkiye'de Trabzon hurması (Diospyros kaki L.) yetiştiriciliğinin sorunları ve geleceği. Black Sea Journal of Agriculture, 1 (2): 38-43.

Özdemir, A. E., Toplu, C., Yıldız, E., Duman, C., Ünlü, M. 2014. Vainiglia Trabzon hurması çeşidinde soğukta muhafazanın burukluğu önlemeye etkisi. 6. Bahçe Ürünlerinde Muhafaza ve Pazarlama Sempozyumu, 22-25 Eylül, Bursa, s. 221-227.

Parmaksız, A, 2004. Gama Spektrometrik Yöntem ile Fosfojipsteki ${ }^{226} \mathrm{Ra},{ }^{232} \mathrm{Th},{ }^{40} \mathrm{~K}$ Aktivitelerinin Ölçülmesi. Gazi Üniversitesi, Fen Bilimleri Enstitüsü, Fizik Anabilim Dalı, Yüksek Lisans Tezi, $43 \mathrm{~s}$.

Parseker Yönel, S, Uylaşer, V. ve Yonak, S. 2008. Trabzon hurmasının bileşimi ve besleyici değeri. Türkiye 10 . Gıda Kongresi, 21-23 Mayıs, Erzurum, s. 339342.

Salih, N. F. 2019. Determination of ${ }^{226} \mathrm{Ra},{ }^{232} \mathrm{Th}$ and ${ }^{40} \mathrm{~K}$ in teeth by use of gamma spectroscopy. Isotopes in Environmental and Health Studies, 55 (1) :80-91. 
Sargın, S.A., Akçiçek, E. ve Selvi, S. 2013. An ethnobotanical study of medicinal plants used by the local people of Alasehir (Manisa) in Turkey. Journal of Ethnopharmacology, 150 (3): 860-874.

Toplu, C., Özdemir, A.E., Yıldız, E., Coşkun, G., Güzel, U., Duman, C. ve Ünlü, M. 2016. Amankaki ve Vainiglia Trabzon Hurması Çeşitlerinde Etanol Uygulamalarının Burukluğu Önlemeye Etkisi. Bahçe Özel Sayı: 7. Uulusal Bahçe Bitkileri Kongresi Bildirileri, Cilt I: Meyvecilik, 390-395.

Tuzcu, Ö. ve Yıldırım, B. 2000. Trabzon hurması (Diospyros kaki L) ve yetiştiriciliği. TÜBITAK TARP Yayınları, Adana.

Vardal, E. 2009. Rize ili Pazar ve Ardeşen İlçelerinde Yetişen Trabzon Hurmalarının (Diospyros kaki L.) Seleksiyon Yolu ve Islahı. Ordu Üniversitesi, Fen Bilimleri Enstitüsü, Bahçe Bitkileri Anabilim Dalı, Yüksek Lisans Tezi, $59 \mathrm{~s}$.

Yıldız, E., Kaplankiran, M. ve Toplu, C. 2012. Genetik kaynaklarımızda yer alan bir meyve türü: Yeșil hurma (Diospyros oleifera Cheng). Mustafa Kemal Üniversitesi Ziraat Fakültesi Dergisi, 17 (1): 41-46.

Ying, L., Brenna, R., Yuen, R. and Hoskins, C. 2015. Spectrum quantification of radium isotopes in hydraulic fracturing wastes. International Journal of Environmental Monitoring and Analysis, 3 (2-1): 7-10.

Yücecan, S. 2008. Optimal Beslenme. T.C. Sağlık Bakanlığı Temel Sağlık Hizmetleri Genel Müdürlüğü Beslenme ve Fiziksel Aktiviteler Daire Başkanlığı, Yayın No: 726, Ankara, Türkiye 